\title{
ENSINO DE HISTÓRIA E O PROJETO “GÊNERO E DIVERSIDADE NA ESCOLA": OS CARTAZES COMO FONTES PARA AS SUBJETIVIDADES
}

\author{
Janine Gomes da Silva \\ Universidade Federal de Santa Catarina (UFSC), Brasil \\ E-mail: janine.gomesdasilva@gmail.com \\ ORCID: https://orcid.org/0000-0003-2866-2981 \\ Robson Ferreira Fernandes \\ Universidade Federal de Santa Catarina (UFSC), Brasil \\ E-mail: rofefe23@gmail.com \\ ORCID: https://orcid.org/0000-0002-4160-4615
}

Data de recebimento: 29/01/2020

Data de aprovação: 25/03/2020

DOI: https://doi.org/10.30612/frh.v22i39.12571

\begin{abstract}
Resumo: Pela importância de se discutir os temas de gênero e diversidade na escola, o presente artigo evoca a ideia geral do Projeto "Gênero e Diversidade na Escola", realizado na Escola de Educação Básica Antônio Lehmkuhl (Águas Mornas - Santa Catarina), a partir do recorte temporal de 2015 a 2016, e pensa os cartazes como fontes para as subjetividades, que serão elencados como objeto de pesquisa. As pessoas que transitam pela escola são compostas de gênero, orientação sexual, identidade de gênero e estão em constante transformação, variando seus interesses e desejos, alterando práticas cotidianas e a forma como se percebem e como vêem os outros. A escola ainda é segregadora e discriminatória para os corpos que transgridem os padrões heteronormativos da sociedade. Um grupo é mais hegemônico do que o outro. As diferenças entre homens e mulheres são tidas como naturais e definidas por diferenças nos corpos biológicos. A normatização dos papéis de gênero é perceptível e afeta as liberdades individuais e de escolhas. Diante desse quadro, torna-se importante conscientizar, sensibilizar e informar alunas/os, professoras/es, funcionárias/os, mães e pais sobre a necessidade urgente do trabalho com questões de gênero e diversidade na escola, contribuindo, desse modo, com a formação humana integral.
\end{abstract}

Palavras-chave: Ensino de História, Gênero e Diversidade, Escola, Cartazes, Escola de Educação Básica Coronel Antônio Lehmkuhl.

\section{TEACHING HISTORY AND THE PROJECT "GENDER AND DIVERSITY AT SCHOOL": POSTERS AS SOURCES FOR SUBJECTIVITIES}

\begin{abstract}
Due to the importance of discussing gender and diversity at school, this article evokes the general idea of the Project "Gender and Diversity at School", carried out at the Escola de Educação Básica Antônio Lehmkuhl (Águas Mornas - Santa Catarina), starting from time frame from 2015 to 2016, and thinks of posters as sources for sujectivities, which will be listed as an object of research. People who pass through the school are made up of gender, sexual orientation, gender identity and are desires, changing daily practices and the
\end{abstract}


way they perceive themselves and how they see others. The school is still segregating and discriminating against bodies that violate society's heteronormative standards. One group is more hegemonic than the other. Differences between men and women are taken for grated and defined by differences in biological bodies. The normalization of gender roles is perceptible and affects individual and choice freedoms. Given this situation, it is important to raise awareness, sensitize and inform students, teachers, employees, mothers and fathers about the urgent need to work with issues of gender and diversity at school, thus contributing to the integral human formation.

Keywords: Teaching History, Gender and Diversity, School, Posters, Escola de Educação Básica Coronel Antônio Lehmkuhl.

\section{ENSEÑANZA DE HISTORIA Y EL PROYECTO “GÉNERO Y DIVERSIDAD EN LA ESCUELA": LOS CARTALES COMO FUENTES DE SUBJETIVIDADES}

Resumen: Debido a la importancia de discutir el género y la diversidad en la escuela, este artículo evoca la ideia general del Proyecto "Género y Diversidad en la Escuela", llevando a cabo en la Escola de Educação Básica Antônio Lehmkuhl (Águas Mornas - Santa Catarina), desde el período de tiempo de 2015 a 2016, y considera los carteles como fuentes de subjetividades, que se enumerarán como objeto de investigación. Las personas que pasan por la escuela están formadas por género, orientación sexual, identidad de género y cambian constantemente, cambiando sus intereses y deseos, cambiando las prácticas diarias y la forma en que se perciben a sí mismos y cómo ven a los demás. La escuela todavía está segregando y discriminando los cuerpos que violan los estándares heteronormativos de la sociedad. Un grupo es más hegemônico que el otro. Las diferencias entre hombres y mujeres se dan por sentadas y se definen por las diferencias en los cuerpos biológicos. La normalización de los roles de género es perceptible y afecta las libertades individuales y de elección. Ante esta situación, es importante crear consciencia, sensibilizar y informar a los estudiantes, maestros, empleados, madres y padres sobre la urgente necesidad de trabajar con temas de género y diversidad en la escuela, contribuyendo así a la formación humana integral.

Palabras clave: Enseñanza de Historia, Género y Diversidad, Escuela, Cartales, Escola de Educação Básica Coronel Antônio Lehmkuhl.

\section{Ensino, Gênero e Diversidade e os Marcos Legais da Educação no Brasil}

A partir das experiências de uma prática pedagógica na Educação Básica, objetivamos problematizar, neste artigo, a possibilidade legal e empírica de trabalhar em sala de aula e no ensino de História as questões de gênero e sexualidades que afetam as subjetividades e o currículo da escola, bem como, a necessidade de construção de espaços de formação pedagógica para que temas como os da diversidade de gênero e sexualidades possam ser abordados sem polêmica. Nesse sentido, direcionamos esse artigo a todos os professores e 
professoras que se veem agindo sob práticas de silenciamento das diferenças - em destaque as de gênero e sexualidades - que são conduzidas pelos padrões de normalidade.

O artigo está organizado em dois blocos: o primeiro apresenta as discussões teóricas das questões de gênero e sexualidades, bem como a legislação vigente da Educação no Brasil e, no segundo, a narrativa do projeto "Gênero e Diversidade na Escola", realizado na Escola de Educação Básica Coronel Antônio Lehmkuhl (EEBCAL) - Águas Mornas/Santa Catarina, entre os anos de 2015 e 2016.

Esta escrita está baseada na importância de se discutir os temas de gênero e diversidade na escola, especialmente nas aulas de História. Quando pensamos em processos educativos logo nos remetemos à escola. Portanto, processos educativos vão além da esfera escolar e sempre estiveram presentes na história da humanidade. Esses processos podem ser entendidos como formas pelas quais as gerações mais jovens eram inseridas na cultura do meio em que nasceram ou a passagem dos conhecimentos relacionados à sobrevivência do grupo para aqueles que vão integrando-se à vida social com participação mais ativa (MANACORDA, 1992). Ou seja, o alerta na história está marcado pelo caráter social da educação, vinculado diretamente ao contexto que a cerca. A partir dessa discussão, Manacorda (1992, p. 6) informa que:

[...] o discurso pedagógico é sempre social, no sentido de que tende, de um lado, a considerar como sujeitos da educação as várias figuras dos educandos, pelo menos nas duas determinações opostas de usuários e de produtores, e, de outro lado, a investigar a posição dos agentes da educação nas várias sociedades da história. Além disso, é também um discurso político, que reflete as resistências conservadoras e as pressões inovadoras presentes no fato educativo e, afinal, a relação dominantes-dominados.

Com isso, pretendemos ter em vista a relevância da questão social e histórica, quanto todos os aspectos que se movimentam nos processos educativos, de modo a atender a educação como uma esfera viva e dinâmica das relações humanas.

A sociedade está em constante mudança e as pessoas variando seus interesses e desejos, alterando práticas cotidianas e a forma como se percebem e como vêem os outros. Durante muito tempo prevaleceu, na maior parte das sociedades, a ideia de que as diferenças entre homens e mulheres eram naturais e definidas por diferenças biológicas. As mulheres teriam nascido com uma aptidão maior para o cuidado com o lar e os filhos, enquanto os homens tinham maior facilidade para trabalhar fora, fazer maior esforço físico e assumir cargos de chefia, entre muitas outras atividades que marcaram as distinções entre os sexos. Esse mesmo discurso era, notadamente, utilizado para justificar a subordinação feminina e as 
relações desiguais entre homens e mulheres. Na divisão binária, a Escola é uma Instituição que transforma crianças em meninos e meninas; quando a professora faz uma fila para meninos e outra para meninas; quando na Educação Física, o professor atribui o esporte do futebol para os meninos e o vôlei para as meninas; quando os comentários de professores durante as aulas subordinam o gênero feminino do masculino; quando aplicam regras e condutas mais ríspidas para os meninos e mais sensíveis e delicadas para as meninas; quando o mundo azul e o rosa pertencem, respectivamente, aos meninos e meninas; etc. Essas são formas violentas educacionais e coercitivas a priori dos desejos e destinos das crianças e jovens. A normatização dos papéis de gênero violenta corpos e cria julgamentos que retira os mesmos de um lugar, que no contexto social não era de seu pertencimento. Foucault, um grande filósofo francês do século XX, dizia, no seu livro Vigiar e Punir (1987, p. 153):

A disciplina "fabrica" indivíduos: ela é a técnica específica de poder que toma os indivíduos ao mesmo tempo como objetos e como instrumentos de seu exercício. Não é um poder triunfante [...]; é um poder modesto, desconfiado, que funciona a modo de uma economia calculada, mas permanente. Humildes modalidades, procedimentos menores, se os compararmos aos rituais majestosos da soberania ou aos grandes aparelhos de Estado.

Percebe-se que os marcos legais que regem a Educação Básica, sutilmente moldam ou colocam em formas as crianças e jovens, num processo que é construído lentamente por vários setores que influenciam as demandas da Educação, ora por naturalidade, ora por interesses econômicos. A desconfiança daquilo que é legitimado como "natural", entendemos que precisa ser contestado e criticado como viés para uma formação humana integral. $\mathrm{O}$ campo educacional marca um elo de manifestações subjetivas no decorrer das vivências na esfera escolar e que possibilitam a reflexão crítica das formas de ser e estar na Escola. Diante do quadro dos marcos legais da educação no Brasil que regem os debates das relações de gênero nas aulas de História no Ensino Básico podemos apresentar a Constituição Federal (BRASIL, 1988), que em seu Art. $3^{\circ}$ define, entre os objetivos fundamentais da República Federativa do Brasil, a promoção "do bem de todos, sem preconceitos de origem, raça, sexo, cor, idade e quaisquer outras formas de discriminação". Já o Art. $5^{\circ}$ traz a conhecida afirmação de que "todos são iguais perante a lei, sem distinção de qualquer natureza" e afirma expressamente a igualdade entre homens e mulheres como preceito constitucional. A Lei de Diretrizes e Bases da Educação Nacional (BRASIL, 1996) reproduz e amplia, em seu Art. $3^{\circ}$, os princípios que devem basear o ensino: "I - igualdade de condições para o acesso e permanência na escola; II - liberdade de aprender, ensinar, pesquisar e divulgar a cultura, o 
pensamento, a arte e o saber; III - pluralismo de ideias e de concepções pedagógicas; IV - respeito à liberdade e apreço à tolerância". O Plano Nacional de Educação 2014-2024 (BRASIL, 2014) define entre suas diretrizes a "superação das desigualdades educacionais, com ênfase na promoção da cidadania e na erradicação de todas as formas de discriminação" e a "promoção dos princípios do respeito aos direitos humanos, à diversidade e à sustentabilidade socioambiental". Nas metas que propõe a universalização do ensino fundamental para toda a população de 6 (seis) a 14 (quatorze) anos e do atendimento escolar para toda a população de 15 (quinze) a 17 (dezessete) anos, encontram-se, dentre as estratégias, a necessidade de fortalecer o acompanhamento e o monitoramento do acesso, da permanência e do aproveitamento escolar em situações de discriminação, preconceitos e violências na escola e o desenvolvimento de políticas de prevenção à evasão motivada por preconceito ou quaisquer formas de discriminação, criando rede de proteção contra formas associadas de exclusão.

O que mudou no Plano Nacional de Educação? Onde era mencionado "São diretrizes do PNE a superação das desigualdades educacionais, com ênfase na promoção da igualdade racial, regional, de gênero e de orientação sexual" passou a ser "erradicação de todas as formas de discriminação". A Base Nacional Comum Curricular (2018) e o Plano Nacional de Educação (BRASIL, 2014) retiraram os termos "gênero" e "orientação sexual", e as mesmas contemplam a noção de múltiplo, diverso, respeito, alteridade; mas também não impedem a abordagem em sala. No contexto conservador e fundamentalista religioso da escrita do Plano Nacional de Educação, há uma massiva política de retirada do termo "gênero" dos Planos de Educação Municipal.

As Diretrizes Curriculares Nacionais para Educação Básica (2013) apontam a necessidade de trabalhar questões ligadas a gênero e sexualidade desde a educação infantil até o ensino médio. Indicam para tanto uma abordagem focada não na padronização de comportamentos ou na reprodução de modelos pré-definidos, mas, ao contrário, na reflexão crítica, na autonomia dos sujeitos, na liberdade de acesso à informação e ao conhecimento, no reconhecimento das diferenças, na promoção dos direitos e no enfrentamento a toda forma de discriminação e violência. Acerca da atualização das Diretrizes Curriculares Nacionais para o Ensino Médio (BRASIL, 2018), no capítulo que fala sobre os sistemas de ensino e da proposta pedagógica, a mesma afirma em seu art. 17, inciso II c, "realização de ações fundamentadas nos direitos humanos e nos princípios éticos, de convivência e participação 
democrática visando a construir uma sociedade livre de preconceitos, discriminações e das diversas formas de violências". Afirma também no art. 27, inciso XV:

[...] promoção dos direitos humanos mediante a discussão de temas relativos à raça e etnia, religião, gênero, identidade de gênero e orientação sexual, pessoas com deficiência, entre outros, bem como práticas que contribuam para a igualdade e para o enfrentamento de preconceitos, discriminação e violência sob todas as formas (BRASIL, 2018, p. 14).

Os Parâmetros Curriculares Nacionais (BRASIL, 1997) estão organizados em Áreas e em Temas Transversais. Há um caderno específico para cada tema, dentre eles, um de Orientação Sexual. O documento é importante para garantir o trabalho com a temática de gênero na Educação Básica. Esse documento é um referencial teórico para o planejamento de professoras/es. Com ele, profissionais da educação podem sentir-se amparados a trabalhar questões como homofobia na escola, visto que a homossexualidade faz parte da orientação sexual.

A Base Nacional Comum Curricular (2018, p. 9-10) nas suas competências gerais, enfatiza a importância do/a estudante ser preenchido/a por noções de respeito e tolerância no percurso da Educação Básica:

7. Argumentar com base em fatos, dados e informações confiáveis, para formular, negociar e defender ideias, pontos de vista e decisões comuns eu respeitem e promovam os direitos humanos, a consciência socioambiental e o consumo responsável em âmbito local, regional e global, com posicionamento ético em relação ao cuidado de si mesmo, dos outros e do planeta. 8. Conhecer-se, apreciar-se e cuidar da sua saúde física e emocional, compreendendo-se na diversidade humana e reconhecendo suas emoções e as dos outros, com autocrítica e capacidade para lidar com elas. 9. Exercitar a empatia, o diálogo, a resolução de conflitos e a cooperação, fazendo-se respeitar e promovendo o respeito ao outro e aos direitos humanos, com acolhimento e valorização da diversidade de indivíduos e de grupos sociais, seus saberes, identidades, culturas e potencialidades, sem preconceitos de qualquer natureza.

No capítulo sobre "As juventudes e o Ensino Médio" (BRASIL, 2018, p. 467), considera-se que há muitas juventudes implica organizar uma escola que acolha as diversidades, promovendo, de modo intencional e permanente, o respeito à pessoa humana e aos seus direitos:

A escola que acolhe as juventudes deve ser um espaço que permita aos estudantes: - compreender que a sociedade é formada por pessoas que pertencem a grupos étnico-raciais distintos, que possuem cultura e história 
próprias, igualmente valiosas, e que em conjunto constroem, na nação brasileira, sua história; - promover o diálogo, o entendimento e a solução não violenta de conflitos, possibilitando a manifestação de opiniões e pontos de vista diferentes, divergentes ou opostos; - combater estereótipos, discriminações de qualquer natureza e violações de direitos de pessoas ou grupos sociais, favorecendo o convívio com a diferença; - valorizar sua participação política e social e a dos outros, respeitando as liberdades civis garantidas no estado democrático de direito; e - construir projetos pessoais e coletivos baseados na liberdade, na justiça social, na solidariedade, na cooperação e na sustentabilidade aos grandes aparelhos de Estado.

A Proposta Curricular de Santa Catarina (2014) teve todo seu conteúdo revisado para atender e estar de acordo com a valorização da diversidade na escola, bem como o respeito às diferenças. Possibilita alcançar a formação humana integral, esse documento tem como um dos princípios formativos a diversidade. A palavra "Gênero" aparece explicitamente em vários momentos no documento (SANTA CATARINA, 2014, p. 57):

Nessa Atualização da Proposta Curricular de Santa Catarina, e considerando as Diretrizes Curriculares Nacionais para Educação e Direitos Humanos, estão em discussão: a educação para as relações de gênero; a educação para a diversidade sexual (orientação sexual e identidade de gênero); a educação e prevenção; a educação ambiental formal; a educação das relações étnicoraciais; e as modalidades de ensino: a educação especial; a educação escolar indígena; a educação do campo e a educação escolar quilombola.

O Currículo Base da Educação Infantil e do Ensino Fundamental do Território Catarinense (SANTA CATARINA, 2019, p. 35), no item 1.2 que elenca a Educação para as relações étnico-raciais, determina que a diversidade é um elemento fundante da atualização curricular: "É fundamental, desse modo, a inclusão, nos componentes curriculares, dos movimentos de direitos humanos, das comunidades tradicionais urbanas e rurais, das relações de gênero e da diversidade sexual".

Portanto, os marcos legais que regem a educação no Brasil e em Santa Catarina, abrem espaços para conscientizar, sensibilizar e informar alunas/os, professoras/es, funcionárias/os, mães e pais sobre a necessidade urgente do trabalho com questões de gênero e diversidade na escola. Desse modo, o ensino poderá contribuir com a formação humana integral, princípio essencial do percurso formativo na Educação Básica. O estímulo ao debate e a reflexão sobre questões de gênero e diversidade na escola contribuem para a desmistificação de tabus e senso comum sobre gênero e sexualidades. Diminuir as situações de preconceito e injustiça no ambiente escolar e trabalhar com temas transversais e que estão contidos nos marcos legais do país. É importante diante dos estudos de gênero e do ensino de 
História, trazer a reflexão sobre gênero enquanto uma categoria útil de análise histórica. Scott (1990, p. 88) irá definir gênero em subconjuntos e inter-relacionado, de duas formas:

(1) o gênero é um elemento constitutivo de relações sociais baseadas nas diferenças percebidas entre os sexos e (2) o gênero é uma forma primária de dar significado às relações de poder. As mudanças na organização das relações sociais correspondem sempre a mudanças nas relações do poder, mas a mudança não é unidirecional.

A partir das problemáticas implícitas nas relações de gênero e ensino, analisar os cartazes como fontes das subjetividades, que se subentende, a partir das discussões de Rolnik (1995), como "transição, exercício que pode ser facilitado pelos instrumentos de que dispomos na prática analítica". A autora em foco traz a responsabilidade ética sobre as práticas analistas para compreender as subjetividades e sua transição no conceito de "clínica", onde há um cansaço das subjetividades pré-estabelecidas perante a ousadia das novas (ROLNIK, 1995, p. 60):

A clínica que praticamos é uma clínica da agonia do homem moderno. O paciente que nos procura está dilacerado entre sua subjetividade moderna que já não se sustenta, e seu estranho que não pára de o aporrinhar, pedindo passagem. Ao acolhermos seu estranho, mesmo no silêncio, ele vai ganhando corpo, e esta transição vai se fazendo. O resto se faz por si só.

Foi-nos permitido abrir discussões acerca do projeto "Gênero e Diversidade na Escola", ocorrido na EEBCAL e vinculado ao Projeto Papo Sério, do NIGS - UFSC. A aproximação dos(as) alunos(as) com a discussão de gênero, com a mobilização de saberes entre os(as) professores(as), o apoio institucional dos(as) gestores(as) e comunidade escolar para o debate, consta um significativo avanço e demonstração de que a partir de uma experiência é possível cruzar e transversalizar os componentes curriculares. Além disso, o projeto propiciou aos estudantes o domínio do conhecimento básico sobre instrumentos de coleta e análise de dados; a organização de grupo de estudos sobre a temática de gênero na escola; o reconhecimento nacional e da comunidade geral sobre a importância do projeto desenvolvido na escola; o reconhecimento de novas práticas pedagógicas para combater qualquer forma de violência e preconceito no ambiente escolar.

Deste modo, como escola, instituição que contribui com a socialização e de educação formal das crianças e jovens, é necessário que todos que trabalham para, com e na escola tenham um conhecimento profundo de suas práticas. Para Belloni (2007, p. 62):

A socialização das novas gerações constitui um dos elementos mais importantes da reprodução social, não apenas cultural, mas econômica e 
política. A sociedade reproduz suas estruturas simbólicas por meio de um processo extremamente complexo de transmissão da cultura: conhecimentos, técnicas, valores, símbolos, representações, normas e papéis sociais são apresentados como saberes imprescindíveis, imagens identitárias atraentes e modelos inelutáveis de comportamento.

A escola, portanto, não é neutra. As subjetividades que lá estão são preenchidas por experiências sociais, pessoais, culturais, políticas, etc. É importante ressaltar que esses sujeitos têm pontos de vista convergentes e divergentes, se apoiam em ideologias e teorias que corroboram suas vivências; e o ensino, enquanto conhecimento formal sistematizado na escola passa a ter um caráter científico e democrático.

\section{O projeto "Gênero e Diversidade na Escola" realizado na Escola de Educação Básica Coronel Antônio Lehmkuhl (2015-2016)}

A Escola de Educação Básica Coronel Antônio Lehmkuhl (EEBCAL), gestada pela Secretaria de Educação do Estado de Santa Catarina, localizada no município de Águas Mornas - SC, cidade com forte influência de imigração alemã, que conserva o viés religioso católico e protestante, e tem como atividade econômica predominante a agricultura, e muitos alunos e alunas trabalham na lavoura com a agricultura familiar.

Os temas de gênero e sexualidades sempre se inserem no planejamento anual do Professor Robson no componente curricular de História da Educação Básica; os mesmos são incorporados e com o desejo de dialogar e esclarecer. Nossa escrita tem como base o projeto "Gênero e Diversidade na Escola" e o eixo do Concurso de Cartazes do NIGS ${ }^{1}$, onde o Professor Robson participou do concurso de cartazes nos editais do Projeto do Papo Sério nos anos de 2014 e 2015, e em 2016 com o edital próprio da EEBCAL.

Com os Projetos intitulados "Direitos Humanos, vulnerabilidade e interseccionalidade: propostas de reflexões práticas a estudantes do Ensino Médio" com o Ensino Médio, e "Expressão de Gênero da infância à juventude e Faces da Homofobia" com o $9^{\circ}$ ano do Ensino Fundamental - Anos Finais, perpassou o objetivo de trazer o debate para toda comunidade escolar a pensar as questões de preconceitos e discriminações relacionadas ao sexo, raça, gênero, entre outras.

1 Projeto de extensão da Universidade Federal de Santa Catarina, que é uma das mais importantes atividades realizadas pelo Núcleo de Identidades e Subjetividades (NIGS) no campo da Educação, articulando gênero, sexualidades, diversidade e direitos humanos. Possuía três eixos de atuação distintos: as oficinas temáticas, o concurso de cartazes e organização de eventos acadêmicos (seminários, intervenções, mesas redondas, debates). Seu tempo de duração ocorreu entre 2007 e 2015. O primeiro concurso de cartazes ocorreu em 2009. 
Ensino de História e o Projeto "Gênero e Diversidade na Escola": os cartazes como fontes para as subjetividades Janine Gomes da Silva; Robson Ferreira Fernandes

Os métodos para a realização foram oficinas de conscientização e sensibilização que contribuíram para a identificação dos/as alunos/as com relação às intersecções, a transversalidade de preconceitos pontuados nos grupos que se encontram em maior situação de vulnerabilidade, tais quais as Lésbicas, Gays, Bissexuais, Travestis e Transexuais ${ }^{2}$. Em seguida, os/as alunos/as dos nonos anos 01 e 02 (Ensino Fundamental - Anos Finais), Primeira, Segunda e Terceira série (Ensino Médio), produziram cartazes sobre a temática do Concurso de Cartazes: Trans-Lesbo-Homofobia e Heterossexismo nas Escolas, promovido pelo Núcleo de Identidades de Gênero e Subjetividades - Projeto de Extensão "Papo Sério"/UFSC.

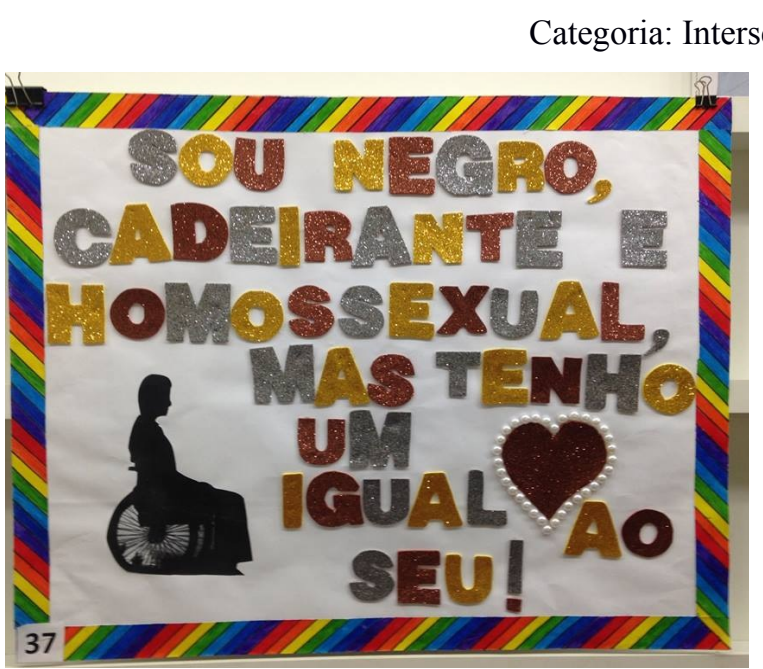

Imagem 1 - Cartaz (Acervo pessoal do autor)

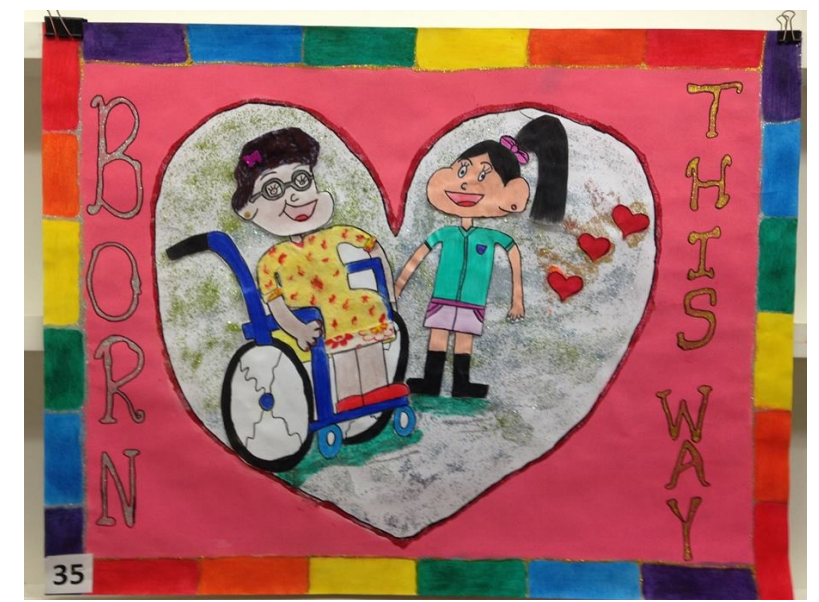

Imagem 2 - Cartaz (Acervo pessoal do autor)

2 Conforme a cartilha Materiais de apoio ao trabalho sobre sexualidades em sala de aula, do Núcleo de Identidades e Subjetividades da Universidade Federal de Santa Catarina, no seu glossário consta: Lésbica: pessoa do sexo/gênero feminino que tem desejos, práticas sexuais e/ou relacionamento afetivo-sexual com outras pessoas do sexo/gênero feminino; Gay: pessoa do sexo/gênero masculino que tem desejos, práticas sexuais e/ou relacionamento afetivo-sexual com outras pessoas do sexo/gênero masculino; Bissexual: pessoa que tem desejos, práticas sexuais e/ou relacionamento afetivo-sexual com pessoas de mesmo sexo/gênero que o dela e com pessoas de sexo/gênero diferentes; Travesti: conforme a definição adotada pela Conferência Nacional LGBT 2008, travesti é uma pessoa que nasce do sexo masculino ou feminino, mas que tem sua identidade de gênero oposta ao sexo biológico, assumindo papéis de gênero diferentes daquele imposto pela sociedade. Muitas travestis modificam seus corpos através de hormonoterapias, aplicações de silicone e/ou cirurgias plásticas, porém vale ressaltar que isso não é regra para todas/os; Transexual: pessoa que possui uma identidade de gênero diferente do sexo designado no nascimento. Homens e mulheres transexuais podem manifestar (ou não) o desejo de se submeterem a intervenções médico-cirúrgicas para realizarem a adequação dos seus atributos físicos de nascença (inclusive genitais) à sua identidade de gênero constituída. No caso de uma pessoa designada ao nascimento como homem e que se identifica como mulher, falamos de "trans-mulher"; no caso de uma pessoa designada ao nascimento como mulher e que se identifica como homem, falamos "trans-homem". 
Ensino de História e o Projeto "Gênero e Diversidade na Escola": os cartazes como fontes para as subjetividades Janine Gomes da Silva; Robson Ferreira Fernandes

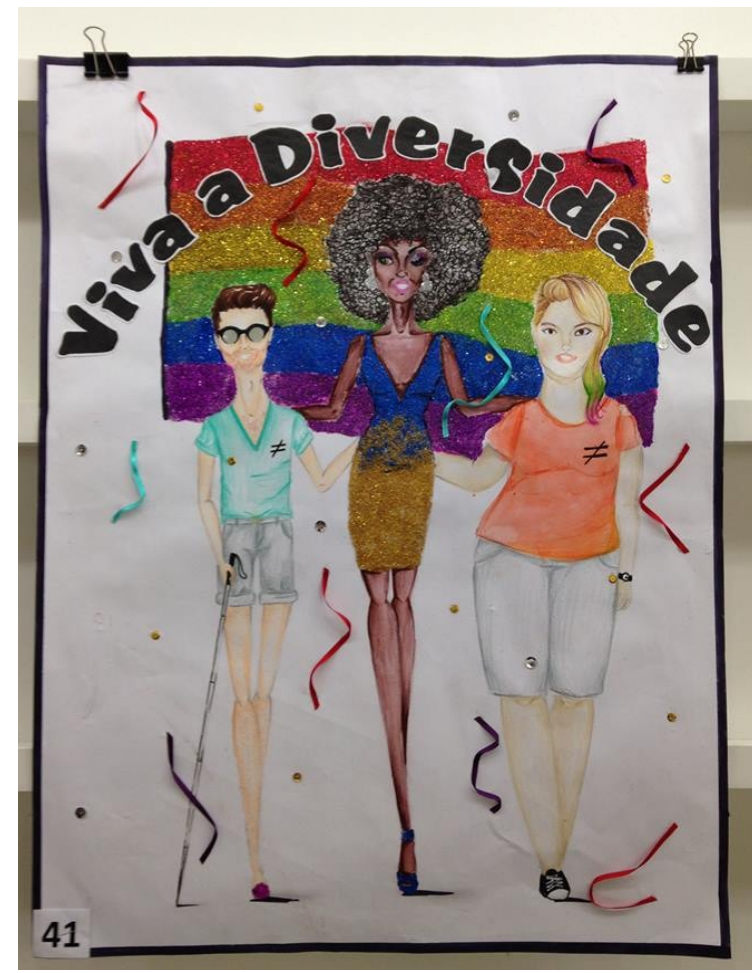

Imagem 3 - Cartaz (Acervo pessoal do autor)

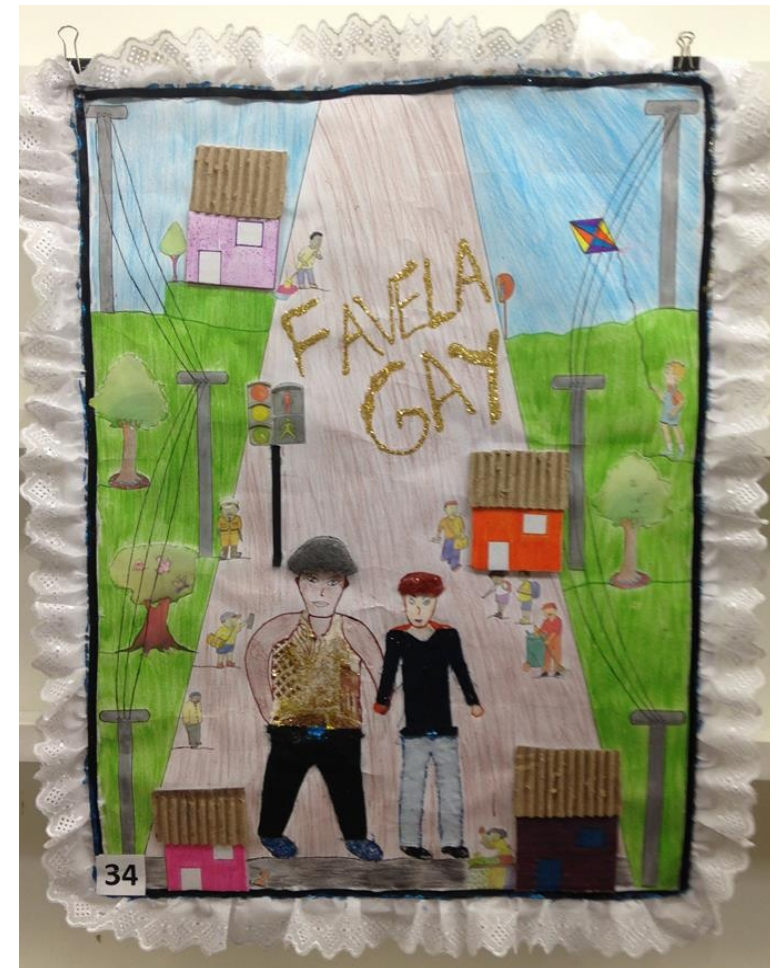

Imagem 4 - Cartaz (Acervo pessoal do autor)

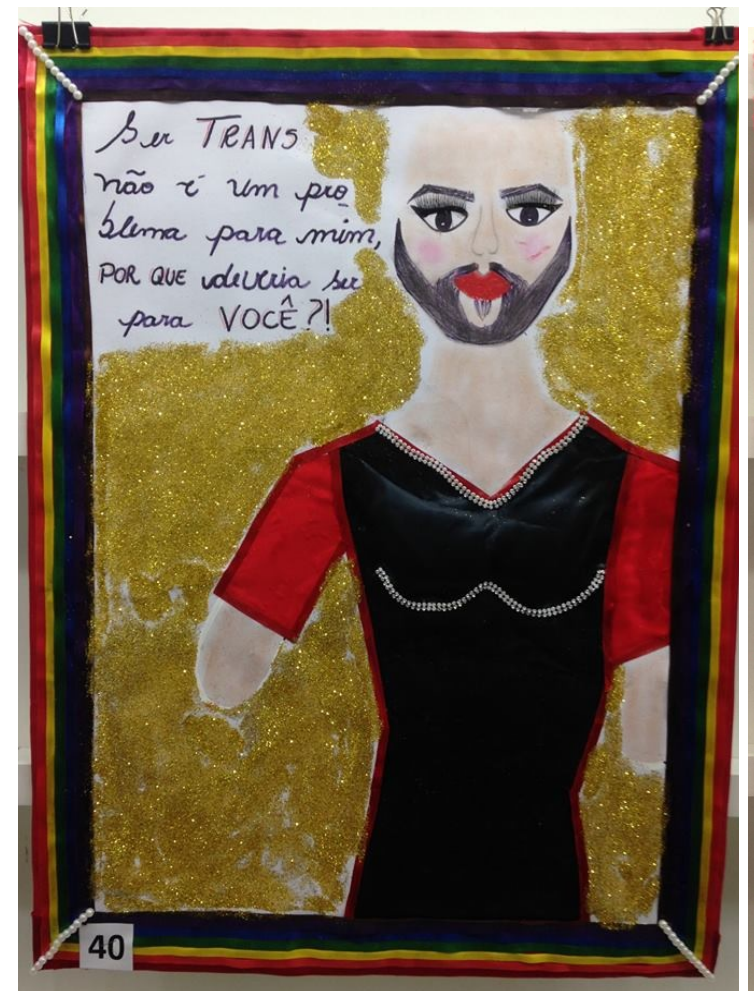

Imagem 5 - Cartaz (Acervo pessoal do autor)

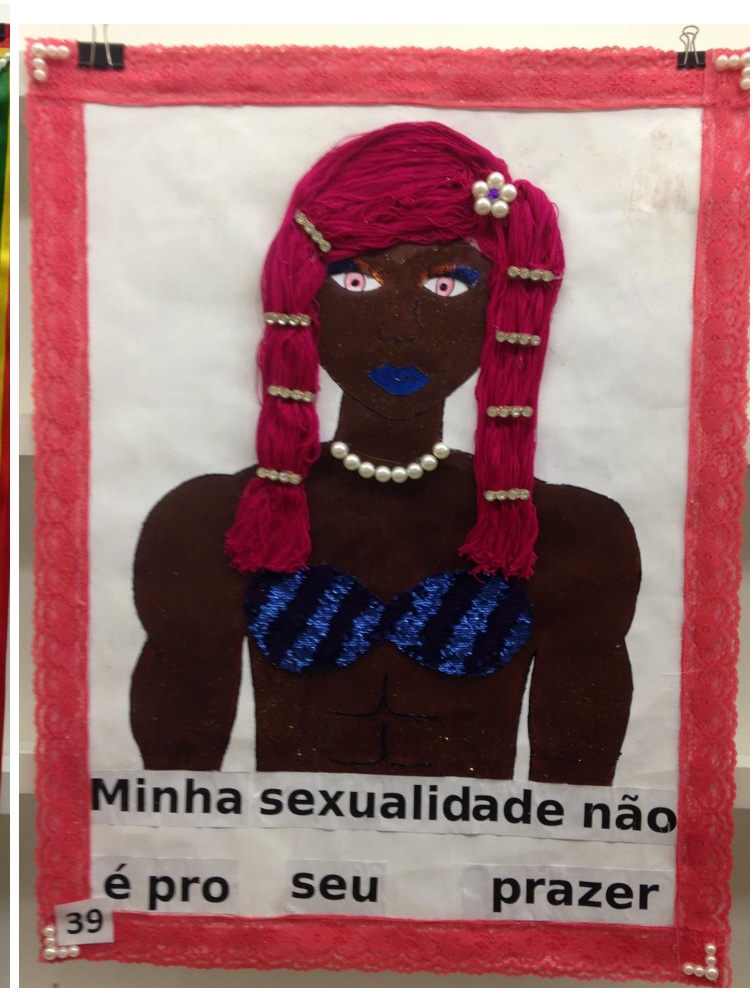

Imagem 6 - Cartaz (Acervo pessoal do autor)

No ano de 2015, as alunas e alunos foram convidados/as a pensarem sobre o conceito de Interseccionalidade, a partir de uma análise teórica para perceberem como os marcadores 
que atravessam os corpos não podem ser pensados isoladamente. Por interseccionalidade (CRENSHAW apud RODRIGUES, 2013, p. 6) entende-se:

A interseccionalidade é uma conceituação do problema que busca capturar as conseqüências estruturais e dinâmicas da interação entre dois ou mais eixos da subordinação. Ela trata especificamente da forma pela qual o racismo, o patriarcalismo, a opressão de classe e outros sistemas discriminatórios criam desigualdades básicas que estruturam as posições relativas de mulheres, raças, etnias, classes e outras.

Com isso, pretendeu fazê-los voltarem seus olhares para outras formas de preconceito e discriminação, além das citadas anteriormente, tais como: racismo, capacitismo ${ }^{3}$, xenofobia, preconceitos de classe, de religião, gordofobia, entre outros. As frases de efeito nos cartazes, tais quais: "Sou negro, cadeirante e homossexual, mas tenho um coração igual ao seu!", "Born this way", "Viva a Diversidade", "Favela Gay", "Ser trans não é um problema para mim, por que deveria ser pra você?", e "Minha sexualidade não é pro seu prazer" justifica as temáticas debatidas nas oficinas e nas provocações que se instalaram na esfera escolar.

A interseccionalidade, ferramenta teórica que nos permite pensar na articulação de várias categorias para entender um fenômeno discriminatório, traz como exemplo, a análise das reflexões dos cartazes, bem como a ideia de uma mulher lésbica negra, a partir de uma perspectiva interseccional, articulará as categorias de gênero, raça, orientação sexual para explicar o fenômeno. Esse cenário pode provocar diversas formas de preconceito, discriminação que culmina em várias formas de violências. Por isso, para compreender as identidades sob perspectiva feminista, é importante pensar que raça não se distancia de gênero, e nem de classe, etc.; Djamila Ribeiro (2018, p. 47) fala que:

O movimento feminista precisa ser interseccional, dar voz e representação às especificidades existentes no ser mulher. Se o objetivo é a luta por uma sociedade sem hierarquia de gênero, existindo mulheres que, para além da opressão de gênero, sofrem outras opressões, como racismo, lesbofobia, transmisoginia, torna-se urgente incluir e pensar as intersecções como prioridade de ação, e não mais como assuntos secundários.

A ideia de violência, popularizada no senso comum, é abordada teoricamente pelo conceito de violências, no plural. Os estudos sobre o tema desmistificam a concepção de violência como agressão física, passando a analisá-la como um conjunto de fatores sociais que

3 O conceito está associado com a produção de poder e se relaciona com a temática do corpo por uma ideia de padrão corporal perfeita; também sugere um afastamento da capacidade e da aptidão dos seres humanos, em virtude da sua condição de deficiência. Para saber mais viste o site AzMina, disponível em: https://azmina.com.br/colunas/o-que-e-capacitismo/. 
montam um ambiente violento. Neste contexto, podemos identificar diversas formas de violências interligadas: a violência verbal, a violência física, a violência simbólica e a violência econômica. Cada qual com suas sutilezas, todas criam feridas, que às vezes, não se curam. Quando pensamos estas violências contra grupos subalternos - definidos como grupos que não preenchem modelos dominantes —, é necessário observar a interseccionalidade de categorias que atuam simultaneamente no processo de discriminação. A violência de gênero, por exemplo, que diz respeito às relações de poder hierárquicas entre homens e mulheres, não pode ser pensada sem que se articulem conjuntamente as categorias raça/etnia, classe social e orientação sexual. Acerca da violência e gênero, Velázquez (2000, p. 12) diz que:

Las definiciones de violencia deben ser útiles para describir las formas de violencia que habitualmente nos encontramos: maltrato físico, abuso emocional, incesto, violación. El reconocimiento de la existencia de estas manifestaciones violentas permitirá organizar conocimientos y prácticas sociales para comprender y apoyar a las víctimas. Pero una definición de violencia de género y por qué se ejerce mayoritariamente sobre las mujeres. La violencia entonces, es inseparable de la noción de género porque se basa y se ejerce en y por la diferencia social y subjetiva entre los sexos.

A oficina de pré-elaboração dos cartazes permitiu que os/as estudantes pudessem também refletir sobre a importância de uma educação com uma perspectiva de respeito aos Direitos Humanos. Foi apresentado o conceito/definição de vulnerabilidade, bem como foram pontuados os grupos históricos que se encontram em maior situação de vulnerabilidade e quais riscos estão expostos. As mulheres estão vulneráveis ao machismo, sexismo e misoginia; homossexuais à homofobia; lésbicas à lesbofobia; travestis, transgêneros e transexuais à transfobia; negras/os ao racismo; populações indígenas ao etnocentrismo. Além disso, foram citadas minorias étnicas, religiosas e culturais, bem como exclusões por conta da aparência física e idade. As conversas também se instalaram na situação de imigrantes e refugiados remetendo à presença de haitianos, comum na região. Também foram citadas como grupos em situação mais vulnerável as populações quilombolas e ribeirinhas.

Sobre interseccionalidade e violências, foram usados vários exemplos práticos para que as/os alunas/os pudessem identificar os cruzamentos e a transversalidade de preconceitos a que uma mesma pessoa possa estar submetida. Por meio do exemplo de uma mulher, negra, gorda e lésbica, as/os alunas/os foram instigadas/os a identificar os preconceitos a que essa pessoa está vulnerável, bem como os marcadores sociais da diferença. Não foi difícil eles e elas identificarem o racismo, a lesbofobia e a gordofobia. Entretanto, tiveram dificuldades em 
mencionar o machismo e o sexismo. Talvez tal fato se tenha dado ainda pela confusão que se faz entre orientação sexual e identidade de gênero, ou não querer mencionar. Como se uma mulher lésbica não pudesse sofrer com o machismo ou com o sexismo. Os/as estudantes assistiram ao clipe do rapper Rico Dalasan, "Aceite-C". Chama atenção por pertencer à periferia, ser negro e gay. Suas músicas são usadas como instrumento de militância e quebra de padrões: gay cantando hip-hop.

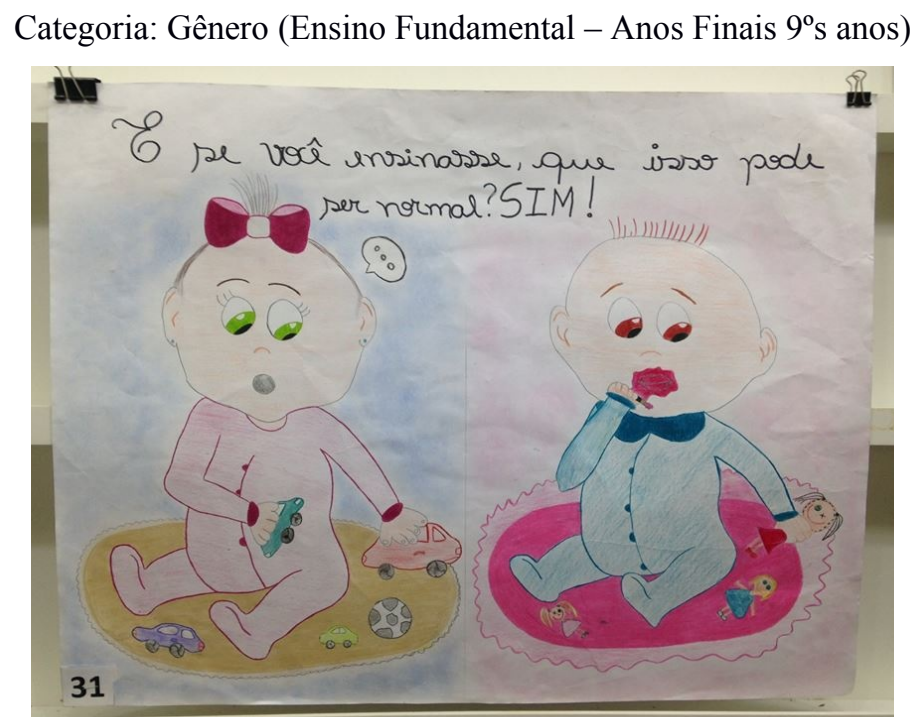

Imagem 7 - Cartaz (Acervo pessoal do autor)

Uma grande ameaça aos Estudos de Gênero se instalou com maior propriedade no (des)governo de Bolsonaro, chamada de Ideologia de Gênero. Frases que serviram de deboche para fundamentar esse discurso saíram de vários protagonistas defensores da "família tradicional brasileira", dos fundamentalismos religiosos, especialmente dos evangélicos, e uma delas, no dia 02 de janeiro de 2019, quando Damares ${ }^{4}$ fala: “Atenção! Atenção! É uma nova era no Brasil: menino veste azul e menina veste rosa" (DAMARES..., 2019). Essa premissa dita um novo mecanismo de poder e organização política de um governo de direita que atenta contra a ciência. Porém, o que ela quer com essa afirmação? Questionar os estudos feministas e abraça o patriarcado desmerecendo a ciência.

A palavra "gênero" é uma categoria de análise dos Estudos Feministas que tem sido utilizada para pensar a construção social das diferenças entre homens e mulheres, conforme explica a historiadora Joan W. Scott (1990). Até recentemente, o senso comum considerava que os comportamentos, ações e espaços na sociedade destinados de maneira diferente para 
homens e mulheres se davam pela diferença biológica dos corpos. Os estudos feministas e de gênero passaram a questionar essa origem biológica e a explicação causal para comportamentos e condutas de mulheres e homens em diferentes sociedades.

É comum pensarmos que aprendemos na nossa educação e socialização que há no mundo dois tipos de pessoas totalmente diferentes: homens e mulheres. Essa construção social de divisão binária entre os sexos começa desde muito cedo, antes mesmo do nascimento. Azul para meninos, rosa para meninas; carrinhos para eles, bonecas para elas. Desta forma, as diversas instituições sociais, como as escolas, as igrejas, a família e a mídia, vão transformando crianças em meninos e meninas, alinhando o gênero ao sexo biológico com o qual as pessoas nascem.

Crescemos aprendendo pelo cinema, pela literatura e pela televisão que as mulheres só são felizes se casarem, se tiverem filhos/as e que devem ficar apenas em casa. Já os homens têm que garantir o sustento da família e circular pelos espaços públicos. Eles têm de ser mais agressivos, enquanto que elas devem ser mais compassivas. Louro (1997, p. 41) afirma que:

Homens e mulheres certamente não são construídos apenas através de mecanismos de repressão ou censura, eles e elas se fazem, também, através de práticas e relações que instituem gestos, modos de ser e de estar no mundo, formas de falar e de agir, condutas e posturas apropriadas (e, usualmente, diversas). Os gêneros se produzem, portanto, nas e pelas relações de poder.

O binarismo de gênero intenta naturalizar questões que são da ordem do cultural, sendo, portanto, mutáveis. Gênero como categoria de análise histórica ajuda a perceber o quanto, em diferentes culturas e momentos históricos, as formas de se lidar com a sexualidade e com as diferenças biológicas se deram de maneira singular.

Assim, na luta por um mundo com mais igualdade, é de suma importância que se respeite os diferentes modos de ser e estar no mundo, de modo que as pessoas possam expressar o gênero da maneira como se sentem confortáveis e não por uma imposição sobre seus corpos. 


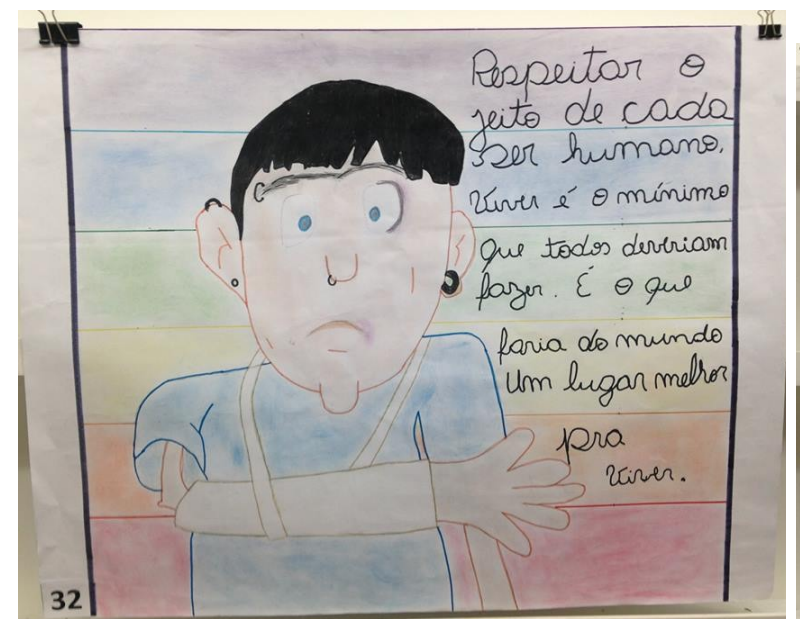

Imagem 8 - Cartaz (Acervo pessoal do autor)

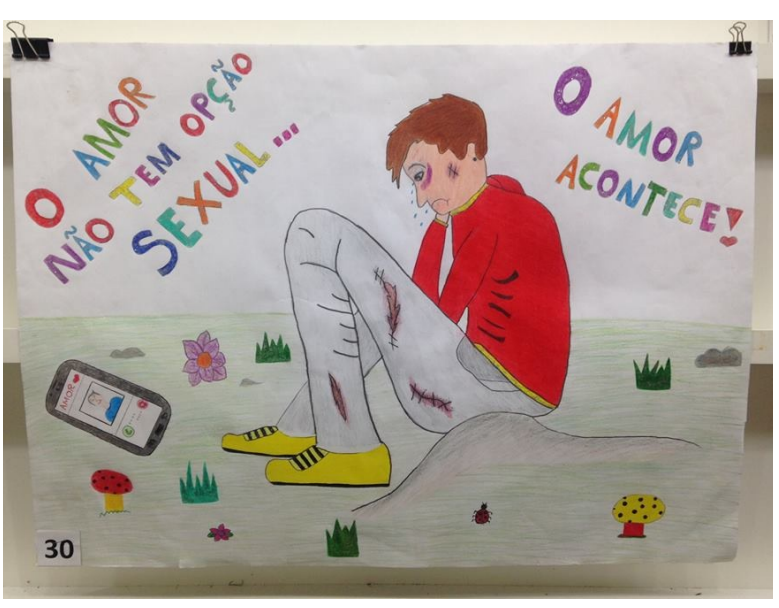

Imagem 9 - Cartaz (Acervo pessoal do autor)

O Ensino Fundamental - Anos Finais, através das turmas dos nonos anos (91 e 92), iniciaram as reflexões sobre as relações de gênero e sexualidades entrando no projeto no ano de 2015.

As reflexões desenvolvidas pelos (as) alunos (as), buscaram compreender a diversidade de experiências, culturas, formas associativas e dinâmicas, que aos quais, para além desses sujeitos, uma humanização crítica e respeitosa possa florescer nas terras de Águas Mornas - Santa Catarina, no coração de jovens impulsionados pelo sentimento de mudança e transformação de seu meio social.

No ano de 2015, além da continuidade dos estudos de Gênero e Sexualidades no Ensino Médio, amplia-se o espaço de divulgação e participação do Concurso de Cartazes para o Ensino Fundamental Anos Finais, especificamente para as turmas dos $9^{\circ} \mathrm{s}$ anos 01 (matutino) e 02 (vespertino), (aproximadamente 25 alunos (as) em cada turma) da EEBCAL.

O desafio inicial e que foi fruto das socializações no decorrer dos encontros, se apresentou com as contestações que emergem a partir das violências, como a lesbofobia, transfobia e homofobia ${ }^{5}$. Uma das atividades consistia na dinâmica da caixa "Pergunte Aí", que foi um objeto de certificação de incertezas, descrenças e objeções anônimas que os/as estudantes puderam depositar as suas dúvidas e perguntas. Questionamentos como: Homofobia é a mesma coisa do que Bullying? Por que alguns homens que se sentem mulher,

Conforme a cartilha "Materiais de apoio ao trabalho sobre sexualidades em sala de aula", do Núcleo de Identidades e Subjetividades da Universidade Federal de Santa Catarina, no seu glossário consta: Homofobia: atitude preconceituosa que hierarquiza as pessoas em função da sua orientação sexual. O termo é usado para se referir às atitudes e condutas de desprezo, discriminação e ódio às pessoas não heterossexuais e, em particular, a gays. Lesbofobia: é a forma de discriminação dupla que articula a intolerância, desprezo, discriminação por causa da orientação sexual, com subordinação ao gênero. Transfobia: despreza às pessoas travestis e transexuais. 
usam roupas femininas e outros usam roupas de homens mesmos? Por que as pessoas acham que homossexualidade é doença, sendo que é dessa forma que elas são felizes? Por que as pessoas têm tanto preconceito? Se você fosse pai e tivesse um filho gay, como você reagiria?, mostraram o interesse e a falta de conhecimento dos temas em discussão.

As violências, plurais e que se manifestam empiricamente, referem-se a agressões e atos violentos que impõem o exercício de um grupo social sobre outro, sendo expressivo de uma relação de dominação, por exemplo, homens sobre mulheres, ricos sobre pobres, nativos contra estrangeiros e migrantes, heterossexuais contra homossexuais, etc. Esses atos requerem a aprovação social que justifica a conduta violenta como instrumento para a subordinação ou a exclusão do grupo discriminado, fazendo com que a violência represente uma ameaça constante contra determinado grupo. A LGBTfobia é tratamento mais cruel e que anula, torna invisível, exclui as pessoas de suas identidades.

O projeto realizado em 2016, agora sem vinculação direta com o "Projeto Papo Sério" - NIGS/UFSC, pois o mesmo recebe cortes financeiros, deu a oportunidade para a EEBCAL andar com os seus próprios pés. O I Concurso de Cartazes sobre Trans-LesboHomofobia e Heterossexismo humanizou os/as estudantes do Ensino Fundamental - Anos Finais e Ensino Médio da Escola de Educação Básica Coronel Antônio Lehmkuhl.

Proporcionar conhecimentos científicos da diversidade sexual e de gênero ainda é um grande impasse, ou tabu para alguns/mas, diante da sociedade que se apresenta com resquícios do patriarcado. Mas o tema está no cotidiano, na sala de aula, nas rodas de conversas, nas famílias e, especialmente, em um dos ambientes que unem os mais diversos posicionamentos e personalidades, que é a escola. Para enfatizar a discussão e expandir o conhecimento as/os estudantes sobre o tema, o "I Concurso de Cartazes sobre Trans-LesboHomofobia e Heterossexismo", trazendo como lema "Escola é lugar de respeito às diferenças e construção da igualdade", foi cunhada uma abordagem teórico-metodológica de forma interdisciplinar através de oficinas e roda de debates em ambiente escolar.

O Concurso, nos mesmos moldes do Concurso de Cartazes do Projeto Papo Sério, fomentou a criação artística de cartazes sobre as questões que discorrem acerca do combate às violências e discriminações LGBTfóbicas em ambiente escolar. Nos cartazes, as temáticas foram diversas: discriminação, responsabilidade da escola, padrões de vida criados pela sociedade, reivindicações do movimento LGBTQI+, adoção por casais homossexuais, entre outras questões, ficaram registradas nas imagens que dizem tudo sobre respeito, amor, igualdade e cidadania. 


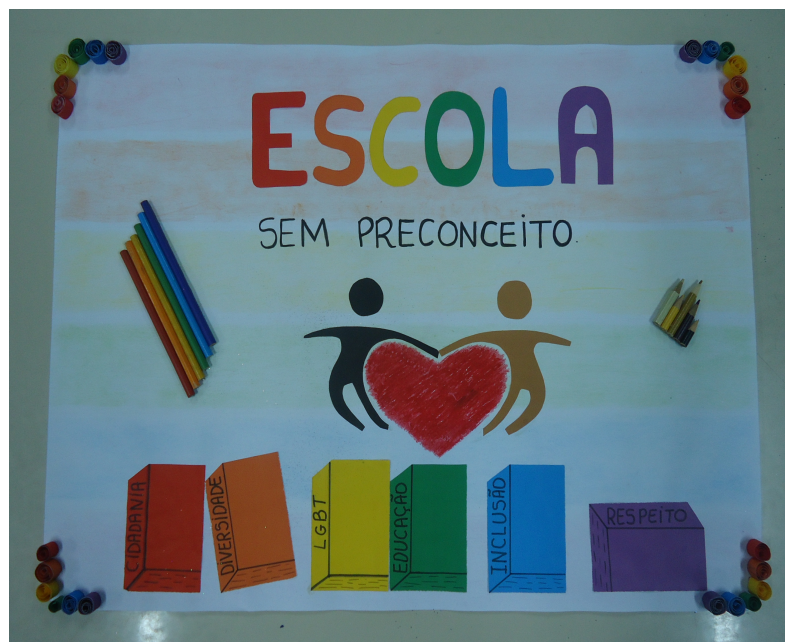

Imagem 10 - Cartaz (Acervo pessoal do autor)

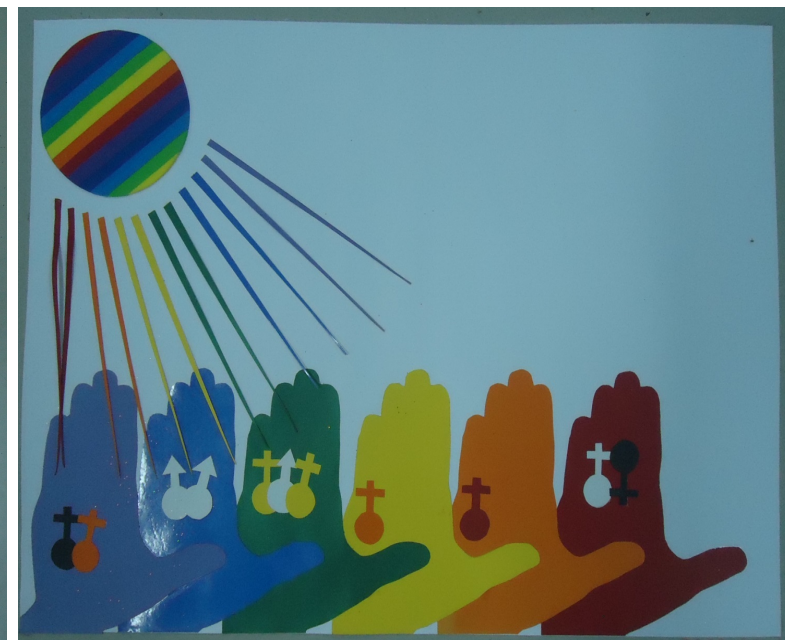

Imagem 11 - Cartaz (Acervo pessoal do autor)

A defesa da responsabilidade da escola diante dos temas em discussão, e especialmente da EEBCAL que mantém seu compromisso como Instituição Escolar Construtora da Igualdade de Gênero, traduz uma realidade que não dá mais de se ausentar: uma sala de aula não é só composta por português e matemática; existem muitas coisas além dessas disciplinas no seu interior. É urgente construir um panorama de respeito e tolerância para que os diversos marcadores sociais dos/as estudantes não sejam possibilidades para as exclusões desses sujeitos da escola. Há um mecanismo na escola que expulsa mais um grupo do que o outro. A escola ainda é segregadora. Devemos implementar e acreditar que um mundo mais justo, igualitário e que respeite as diferenças seja possível com a contribuição da educação. Fazer da escola um lugar em que aqueles e aquelas por anos invisibilizadas/os sejam reconhecidas/os, valorizadas/os e respeitadas/os. A Diversidade e as Diferenças vivem e habitam a escola. Professores/as não podem ser negligentes; devem educar para a valorização da diversidade e o respeito às diferenças. Louro (1997, p. 57) diz que:

Diferenças, distinções, desigualdades... A escola entende disso. Na verdade, a escola produz isso. Desde seus inícios, a instituição escolar exerceu uma ação disjuntiva. Ela se incumbiu de separar os sujeitos - tornando aqueles que nela entravam distintos dos outros, os que a ela não tinham acesso. Ela dividiu também, internamente, os que lá estavam, através de múltiplos mecanismos de classificação, ordenamento, hierarquização. A escola que nos foi legada pela sociedade ocidental moderna, começou por separar adultos de crianças, católicos de protestantes. Ela também se fez diferente para os ricos e para os pobres e ela imediatamente separou os meninos das meninas. 
Assim como os processos sociais são históricos, construir compreensões sobre a História também o é, e isso significa discutir sobre sua relatividade conforme os períodos pelos quais passa. Nos últimos anos, por exemplo, ensinar História se tornou uma resposta a demandas e desafios que envolviam uma renovação do olhar sobre a prática do ensino, bem como da prática enquanto produção de saber histórico. Diante das novas produções de saberes no Ensino de História, Bittencourt (BITTENCOURT, 2011, p. 95) argumenta que:

As análises sobre a história do ensino de História e constituição da memória social têm sido problematizadas a partir das lutas dos movimentos sociais que, dentre outras reivindicações, exigem os estudos sobre novos sujeitos relegados e omitidos pela história acadêmica e escolar.

Os chamados problemas de gênero (sexualidade, diversidade, violência de gênero, homo/lesbo/transfobia, direitos das mulheres, pertença histórica) se tornaram pauta necessária dentro e fora das salas de aula e em muitos casos dentro ou fora da História enquanto disciplina. Considerando os problemas de gênero como sendo também o conjunto de discursos disseminados (parlamentares, mídia, profissionais liberais, empresários, legislações) e que trazem em seu bojo o conservadorismo, a misoginia, a homofobia, sem esquecer-se de relacioná-los a vida social mais ampla de um país que possui altos índices de violência contra mulheres e LGBTQI+ como o Brasil, as reflexões propostas buscam compreender a diversidade de experiências, culturas, identidades que contribuem para uma humanização crítica e respeitosa na consciência de jovens impulsionados pelo sentimento de mudança e revolução social.

As desigualdades sociais advindas da construção social da diferença entre o que é considerado "masculino" e o que é "feminino" geram múltiplas violências e opressões. As desigualdades são aprendidas dentro e fora da escola, porém dentro da escola essas desigualdades se reproduzem.

A partir da perspectiva da escola como um reflexo ativo e dialético da sociedade uma questão fundamental para a construção dessa formação foi (e continua sendo) desconstruir e desvestir os conceitos e preconceitos já estabelecidos pela sociedade.

O momento é de quebra de paradigmas com intervenções na escola, de revisão de nossos conceitos. O debate é pertinente ainda em tempos de conservadorismo radical. Esclarecer, conscientizar e relacionar o assunto com as práticas cotidianas é entender os corpos que transitam pela escola e que formam a sociedade. Nada se finda nessa escrita, tudo se inicia. Essa premissa nos faz despertar para o novo na Educação. Novo que pode ser velho. 
Novo que pode tirar o sossego de alguns. Novo que possibilita sair da zona de conforto. Novo para novos sujeitos. Novo para o século XXI.

\section{Referências}

BELLONI, Maria Luiza. Infância, Mídias e educação: revisitando o conceito de socialização. Caderno Perspectiva, Florianópolis, v. 25, n. 1, p. 41-56, jan./jun. 2007.

BITTENCOURT, Circe Fernandes. Abordagens históricas sobre a História Escolar. Educ. Real. Porto Alegre, v. 36, n.1, p. 83-104, jan./abr. 2011.

BRASIL. Base Nacional Comum Curricular (BNCC). Brasília: MEC. 2018. Disponível em: http://basenacionalcomum.mec.gov.br/images/BNCC_20dez_site.pdf.

BRASIL. Resolução $n^{\circ}$ 3, de 21 de novembro de 2018. Atualização das Diretrizes Curriculares Nacionais para o Ensino Médio. Ministério da Educação. Brasília: MEC, CNE, CEB, 2018.

BRASIL. Plano Nacional de Educação (2014-2024). Brasília, DF: Senado Federal, 2014.

BRASIL. Diretrizes Curriculares Nacionais Gerais da Educação Básica. Ministério da Educação. Brasília: MEC, SEB, DICEI, 2013.

BRASIL. Parâmetros Curriculares Nacionais: introdução aos parâmetros curriculares nacionais. Secretaria de Educação Fundamental. Brasília: MEC/SEF, 1997.

BRASIL. Lei de Diretrizes e Bases da Educação Nacional. Brasília, DF: Senado Federal, 1996. Disponível em: http://www.planalto.gov.br/ccivil_03/leis/19394.htm.

BRASIL. Constituição da República Federativa do Brasil. Brasília, DF: Senado Federal, 1988. Disponível em: http://www.planalto.gov.br/ccivil_03/constituicao/constituicao.htm.

DAMARES Alves diz que "menino veste azul e menina veste rosa". [S. 1.: s. n.], 3 jan. 2019.

1 vídeo $(40 \mathrm{~s})$. Publicado pelo canal Poder360. Disponível em: https://www.youtube.com/watch?v=q6X3-nXjmv4\&feature=youtu.be.

FOUCAULT, Michel. Vigiar e Punir. 7. ed. Petrópolis: Vozes, 1987.

LOURO, Guacira Lopes. Gênero, sexualidade e educação. Uma perspectiva pósestruturalista. Petrópolis, Rio de Janeiro: Vozes, 1997.

MANACORDA, M. A. História da Educação: da antiguidade aos nossos dias. 2. ed. São Paulo: Cortez/Autores Associados, 1992.

RIBEIRO, Djamila. Quem tem medo do feminismo negro? São Paulo: Companhia das Letras, 2018.

RODRIGUES, Cristiano. Atualidade do Conceito de Interseccionalidade para a Pesquisa e Prática Feminista no Brasil. In: SEMINÁRIO INTERNACIONAL FAZENDO GÊNERO, 10., 2013, Florianópolis. Anais eletrônicos [...]. Florianópolis: UFSC, 2013. p. 1-12. ISSN 2179-510X.

ROLNIK, Suely. Subjetividade e História. Exposição em mesa redonda no curso de Psicanálise do Instituto Sedes Sapientiae, em 17.09.92. Rua, Campinas, v. 1, n. 1, p. 49-61, 1995. 
SALA, Arianna; GROSSI, Miriam Pillar (Coord.). Materiais de Apoio ao Trabalho sobre sexualidades em sala de aula, NIGS/UFSC, Florianópolis, 2014.

SANTA CATARINA. Governo do Estado. Secretaria de Estado da Educação. Currículo Base da Educação Infantil e do Ensino Fundamental do Território Catarinense. Estado de Santa Catarina. Secretaria do Estado de Educação, 2019.

SANTA CATARINA. Governo do Estado. Secretaria de Estado da Educação. Proposta Curricular de Santa Catarina: formação integral na educação básica. Estado de Santa Catarina. Secretaria do Estado de Educação, 2014.

SCOTT, Joan. Gênero: uma categoria útil de análise histórica. Revista Educação \& Realidade, v. 15, n. 2, p. 71-89, 1990.

VELÁZQUEZ, Susana. Violencia de Género, violencias cotidianas. Ponencia. Programa de Actualización sobre violencia de género. Asociación de Psicólogos de Buenos Aires. Buenos Aires: Editorial Paidós, 2000. 